ISSN 0258-7122 (Print), 2408-8293 (Online)

Bangladesh J. Agril. Res. 44(2): 355-365, June 2019

\title{
CONSTRAINTS TO LIVELIHOOD DIVERSIFICATION OF RURAL FARMERS IN SELECTED AREAS OF PATUAKHALI DISTRICT
}

\author{
P. K. MITTRA ${ }^{1}$ AND M. G. R. AKANDA ${ }^{2}$
}

\begin{abstract}
The present study was aimed at determining the constraints confronted by the farmers in livelihood diversification. The purposes of this study were to determine the extent and nature of livelihood diversification of the farmers and also to explore relationships of 13 selected characteristics of the farmers with their livelihood diversification. There were a total of 1270 farmers in the 5 villages constituted the population of the study, out of which 10 percent of the total farmers were selected through simple random sampling technique. This gave a sample size of 127 such farmers. Data were collected by the researcher himself with the help of pre-tested interview schedule during 15 February 2013 to $30 \mathrm{March}$, 2013. The livelihood diversification scores of the respondents ranged from 0.22 to 0.79 with an average of 0.41 . It is seen that more than half of the farmers $53.5 \%$ had medium level of livelihood diversification compared to 19.7 percent of them having low livelihood diversification and 26.8 percent had high livelihood. Out of 13 selected characteristics of the farmers, seven of those viz. education, family education, income generating experience, household annual income, communication exposure, organizational participation and attitude towards livelihood diversification had positive significant relationship with livelihood diversification.
\end{abstract}

Keywords: Livelihood, Diversification, Constraints, Rural Farmers.

\section{Introduction}

Livelihood diversification (LD) is a key strategy by which people in many parts of the world try to make ends meet and improve their well-being. Livelihood diversification refers to a continuous adaptive process whereby households add new activities, maintain existing ones or drop others, thereby maintaining diverse and changing livelihood portfolios. The farmers are looking for diverse opportunities to increase and stabilize their incomes, which are determined by their portfolio of assets - social, human, financial, natural and physical capital (Ellis, 1999). Livelihood diversification as a concept is emerging as one of the survival strategy of rural households in developing countries (Ellis 2000, Bryceson, 2000). A majority of rural producers have historically diversified their productive activities to encompass a range of other productive areas. In other words, very few of them collect all their income from only one source, hold all

\footnotetext{
${ }^{1}$ Assistant Professor, Department of Basic Science, Patuakhali Science and Technology University (PSTU), Khanpura, Babugonj, Barisal, ${ }^{2}$ Professor, Department of Agricultural Extension and Rural Development, PSTU, Dumki, Patuakhali, Bangladesh.
} 
their wealth in the form of any single asset, or use their resources in just one activity (Barrett et al., 2001).

The agricultural sector is plagued with problems which include soil infertility, infrastructural inadequacy, risk and uncertainty and seasonality among others. Thus, rural households are forced to develop strategies to cope with increasing vulnerability associated with agricultural production through diversification, intensification and migration or moving out of farming (Ellis, 2000). In other words, the situation in the rural areas has negative welfare implications and predisposes the rural populace to various risks which threaten their livelihoods and their existence. As a result of this struggle to survive and in order to improve their welfare, off-farm and non-farm activities have become an important component of livelihood strategies among rural households.

The growing interest in research on rural off-farm and non-farm income in rural economies is increasingly showing that rural peoples' livelihoods are derived from diverse sources and are not as overwhelmingly dependent on agriculture as previously assumed (Gordon and Craig, 2001). This could be owing to the fact that a diversified livelihood, which is an important feature of rural survival and closely allied to flexibility, resilience and stability is less vulnerable than an undiversified one, this is due to the likelihood of it being more sustainable over time and its ability to adapt to changing circumstances. In addition, several studies have reported a substantial and increasing share of off-farm income in total household income (Ruben and Van den Berg, 2001). Reasons for this observed income diversification include declining farm incomes and the desire to insure against agricultural production and market risks (Matsumoto et al., 2006). In other words, while some households are forced into off-farm and non-farm activities, owing to less gains and increased uncertainties associated with farming (crop and market failures), others would take up off-farm employment when returns to off-farm employment are higher or less risky than in agriculture. Mainly, households diversify into non-farm and off-farm activities in their struggle for survival and in order to improve their welfare in terms of health care, housing, sustenance, covering, etc. Thus, the importance and impact of nonagricultural activities on the welfare of rural farm households can no longer be ignored.

An understanding of the significance and nature of non-farm and off-farm activities (especially its contribution to rural household income or resilience) is of utmost importance for policy makers in the design of potent agricultural and rural development policies. Further, the rising incidence of low level of welfare of rural households, that remains unabated despite various policy reforms undertaken in the country, requires a deeper understanding of the problem and the need to proffer solutions to the problem through approaches that place priority on the poor and ways on which rural households through diversification can maintain their livelihood. However, Constraints confronted by the farmers in 
livelihood diversification, find out the socio-demographic characteristics of the respondents and find out the sources of livelihood of the farmers are three specific objectives which gave proper direction of this study.

\section{Materials and Methods}

Sampling procedure and sample size: The study was conducted at Dumki Upazila of Patuakhali district where a scope of livelihood diversification exists to be pursued as the study was concerned with the livelihood diversification of the farmers. All the farm household heads except the absentees of Dumki Upazila constituted the population of the study. Data were collected from a sample rather than the whole population. Multi-stage random sampling technique was used for the selection of sample. Dumki Upazila is consisted of 5 unions out of which three unions namely, Angaria, Muradia and Sreerampur were selected randomly at the first stage. The villages under these three unions were listed. In the third stage, 10 percent of the villages of the three unions were randomly selected. Thus, Angaria union included 2 villages, Muradia union 1 village, and Sreerampur included 2 villages. All the farm household heads of these 5 villages were listed with the help of Sub-Assistant Agricultural Officers, local Union parishad personnel, and the local leaders of concerned villages. There were a total of 1270 such farm household heads which constituted the sampling population for this study. At the final stage, 10 percent of the farm household heads of each village was randomly selected as sample by using a Table of Random Numbers. Thus, the sample size stood at 127.

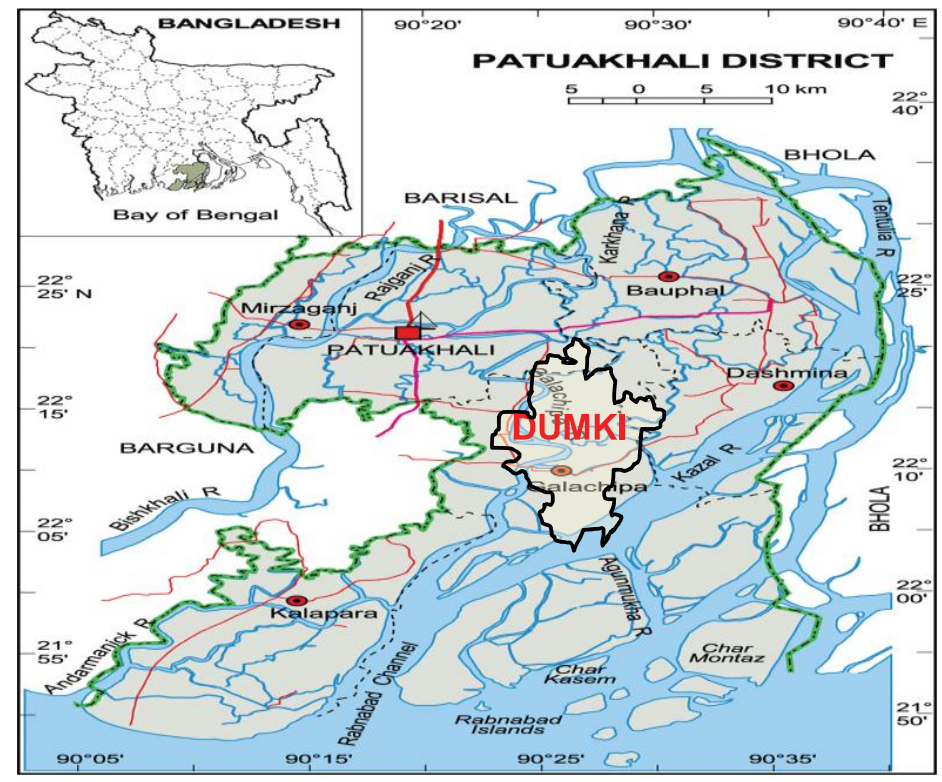

Fig. 1. Map showing the data collection site (Dumki) at Patuakhali District of Bangladesh. 
Analytical Techniques: Independent variables of the study were measured following standard techniques such as age was measured in years, education was measured in schooling years, family size is actual number of the family members, income generating experience was measured in years, training experience was measured in day, household farm size was measured in hectare, household annual income was measured in taka. Livelihood diversification pursued by the farmers was taken as the dependent variable of the study. Simpson diversification index (SDI) was used to measure the livelihood of the farmers. Diversification index was measured with the help of Simpson index of diversity. The Simpson index of diversity is defined as:

$$
\mathrm{SID}=1-\sum(\mathrm{Pi})^{2}
$$

Where Pi as the proportion of income coming from source. The value of SID always falls between 0 and 1 . If there is just one source of income, $\mathrm{Pi}=1$, so $\mathrm{SID}=0$. As the number of sources increases, the shares $(\mathrm{Pi})$ decline, as does the some of the squared shares, so that SID approaches to 1 . If there are $\mathrm{k}$ sources of income, then SID falls between 1-1/k. Accordingly farmers with most diversified income would have the largest SID, and less diversified incomes are associated with the smallest SID. For least diversified farmers (i.e. those depending on a single income source) SID takes on its minimum value of 0 . The upper limit SID is ' 1 ' which depends on the number of income sources available and their shares. The higher the number of income sources as well as more evenly distributed the income shares, the higher the value of SID. The Simpson Index of Diversity is affected both by the number of income sources as well as by the distribution of income between different sources (balance). The more uniformly distributed is the income from each source, the SID approaches to 1 .

\section{Results and Discussion}

\section{Problem Faced in Livelihood Diversification}

The problem scores of the farmers ranged from 40 to 67 against the possible range of 0 to 75 . The mean and standard deviation were 53.49 and 6.28 respectively. Slightly more than two fifth (42.75 percent) of the farmers had medium problem compared to 34.65 percent of them having low and 22.60 percent high problem were found in this area. Thus majority (63.35 percent) of the farmers has medium to high problem in Livelihood Diversification. 
Sources of livelihood problems of the respondent farmers.

\begin{tabular}{|c|c|c|c|}
\hline $\begin{array}{l}\text { Sl. } \\
\text { No. }\end{array}$ & Constraints faced & Mean score & Rank order \\
\hline 01. & Lack of own capital & 1.80 & $1^{\mathrm{st}}$ \\
\hline 02 . & Shyness in doing socially underestimated works & 1.72 & $2^{\text {nd }}$ \\
\hline 03. & Lack of opportunity & 1.67 & $3^{\text {rd }}$ \\
\hline 04. & Inadequate family labor & 1.66 & $4^{\text {th }}$ \\
\hline 05 . & Poor communication facilities & 1.55 & $5^{\text {th }}$ \\
\hline 06. & Limited availability of education and skill training & 1.50 & $6^{\text {th }}$ \\
\hline 07. & Lack of family encouragement & 1.50 & $7^{\text {th }}$ \\
\hline 08. & Inadequate income generation than primary activities & 1.50 & $8^{\text {th }}$ \\
\hline 09. & Women's working not recognized & 1.47 & $9^{\text {th }}$ \\
\hline 10. & Lack of needed assistance & 1.43 & $10^{\text {th }}$ \\
\hline 11. & Inadequacy of desired occupation & 1.32 & $11^{\text {th }}$ \\
\hline 12. & Much competition in the market & 1.24 & $12^{\text {th }}$ \\
\hline 13. & Inadequate labor force & 1.23 & $13^{\text {th }}$ \\
\hline 14. & Lack of access to appropriate technology & 1.20 & $14^{\text {th }}$ \\
\hline 15. & Lack of marketing & 1.08 & $15^{\text {th }}$ \\
\hline 16. & Lack of raw materials & 1.05 & $16^{\text {th }}$ \\
\hline 17. & Primary activities not leaving enough time to pursue & 1.02 & $17^{\text {th }}$ \\
\hline 18. & Inadequate loan & 1.01 & $18^{\text {th }}$ \\
\hline
\end{tabular}

Livelihood diversification scores of the respondents ranged from 0.22 to 0.79 . The mean was 0.43 . The farmers were classified into three groups based on these observed scores as "low livelihood diversification"(up to 0.29), "medium livelihood diversification" (more than 0.29 to 0.58 ), and "high livelihood diversification" (above 0.58). It is seen that more than fifty percent (53.50 percent) of the farmers had medium level of livelihood diversification compared to 19.70 percent of them having low livelihood diversification and 26.80 percent, high livelihood diversification. However, Habiba (2012) also reported that more than fifty percent ( 54.2 percent) of the rural women farmers had medium level of livelihood diversification compared to 18 percent of them having low livelihood diversification and 27 percent, high livelihood diversification. Saha and Ram (2010) also obtained similar results from their respective studies. Correlation analysis was done. In order to determine the relationship between the selected 13 characteristics (independent variables) of the farmers with their livelihood diversification (dependent variable), coefficient of correlation was computed between the variables. The results of correlation analysis are shown in Table 4. 
360

MITTRA AND AKANDA

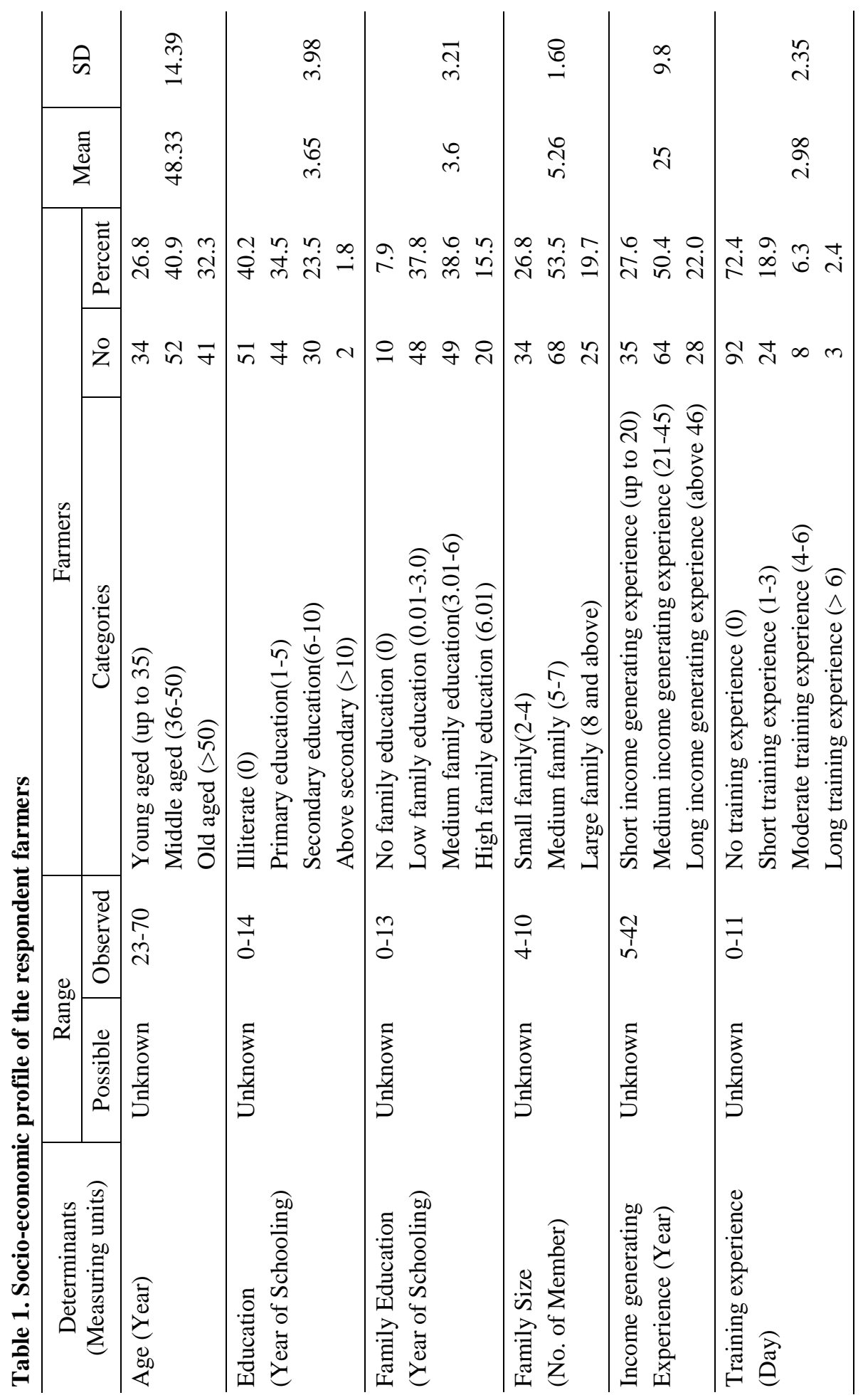




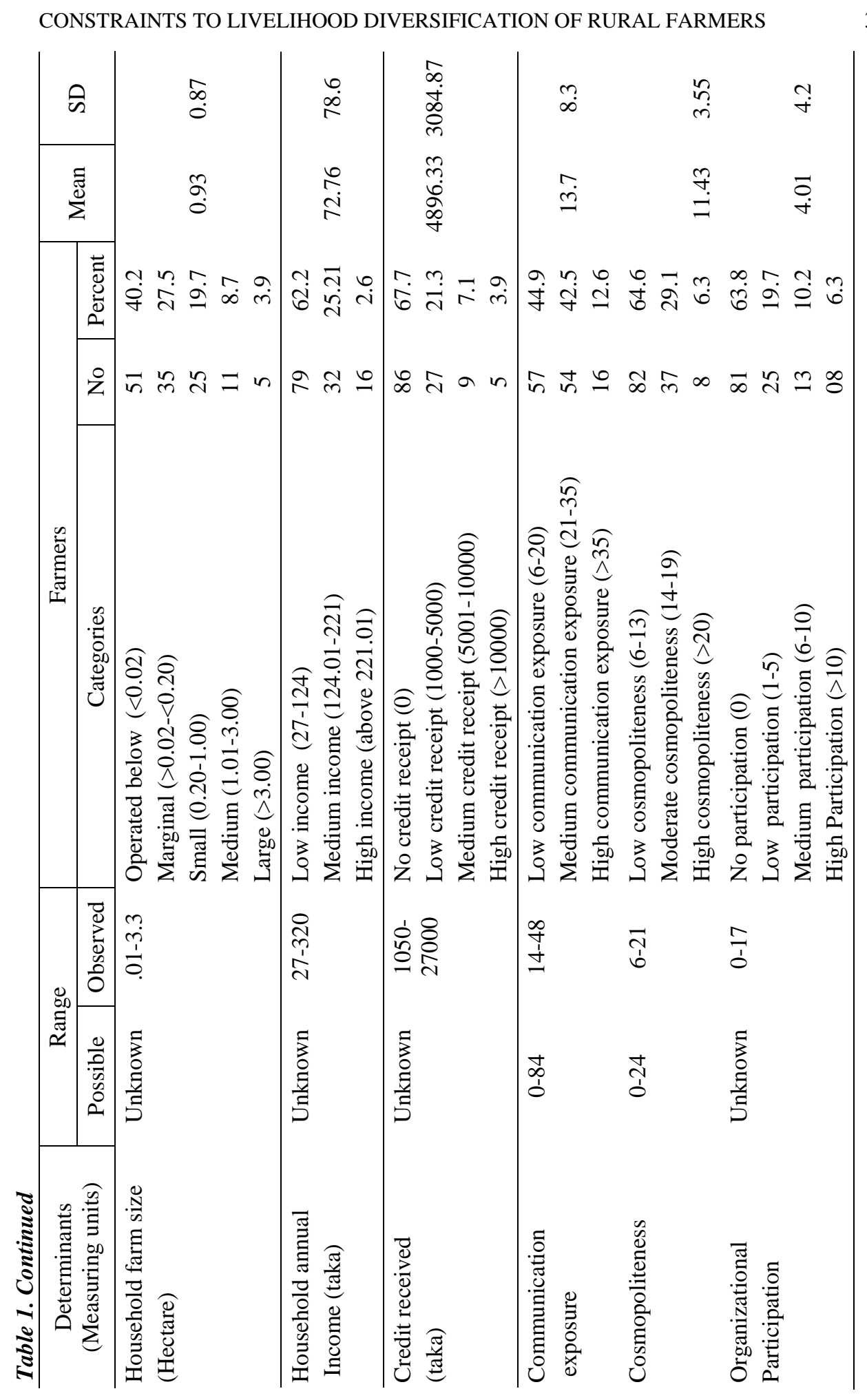




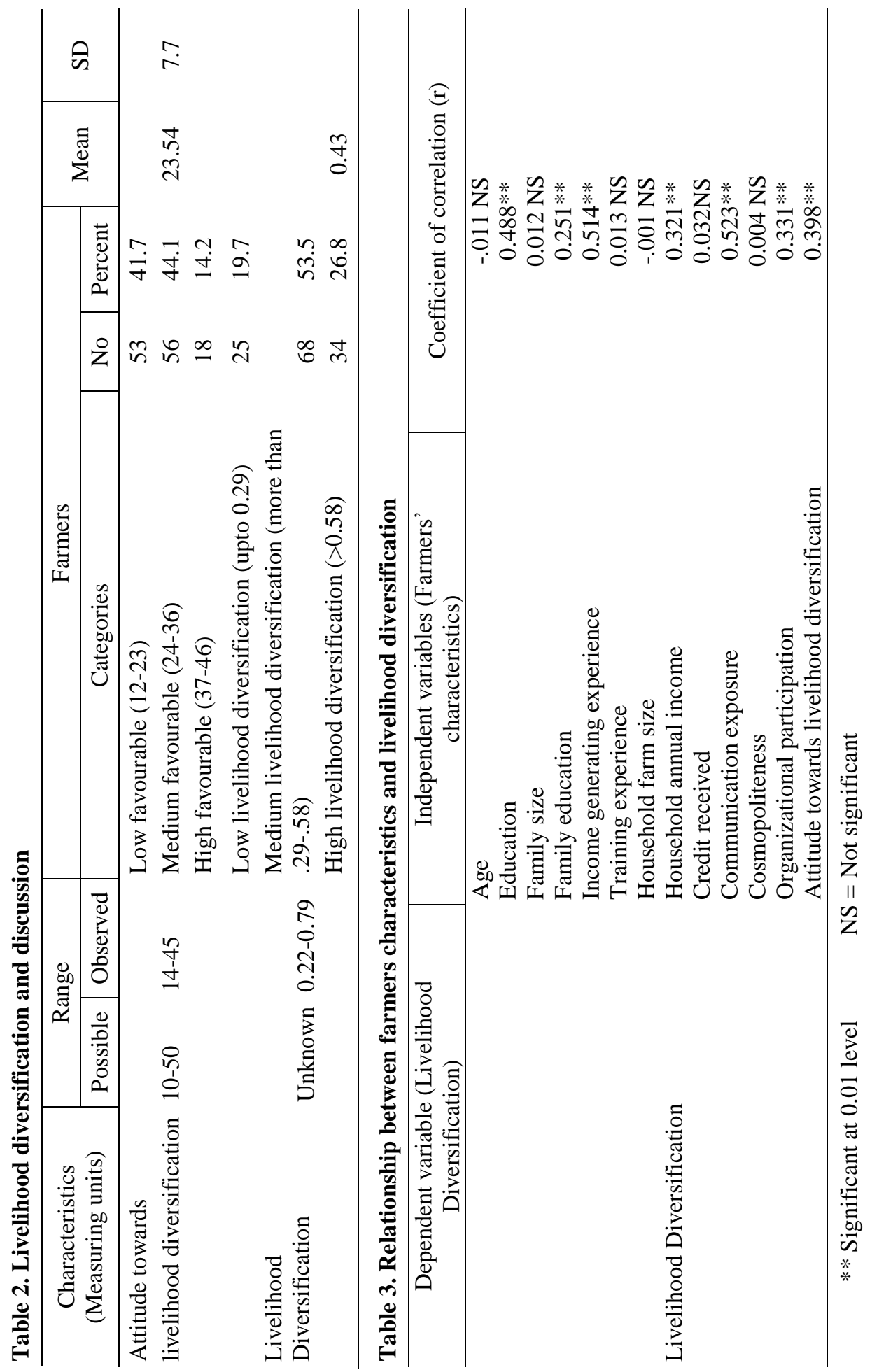


Out of 13 independent variables, 7 of those showed positive significant relationships with the livelihood diversification of the farmers. The variables that showed significant relationships were education $\left(0.488^{* *}\right)$, family education $\left(0.251^{* *}\right)$, income generating experience $\left(0.514^{* *}\right)$, household annual income $\left(0.321^{* *}\right)$, communication exposure $(0.523 * *)$, organizational participation $(0.331 * *)$, attitude towards livelihood diversification $(0.398 * *)$. It means that if there is any increase in these variables there would be positive change in livelihood diversification of the farmers, i.e. higher the values of those selected variables, the greater the livelihood diversification of the farmers. Findings of the study may be concluded that education was found significantly correlated to livelihood diversification meaning that, a person having higher education level is likely to have higher livelihood diversification. From the findings, it could be concluded that, education can bring desirable changes in human behavior which ultimately helps diversify his/her livelihoods.

Income generating experiences was found significantly correlated to livelihood diversification which means a person having higher income generating experiences will have higher livelihood diversification and vice versa. From the findings it could be concluded that, a person who used to have skill with income generation through which s/he can earn money and can diversify his/her livelihood status.

Communication exposure and organizational participation was found to have significant relationship with livelihood diversification which indicates that a person with high communication exposure and organizational participation is able to diversify his/her livelihood. From the findings, it could be concluded that, if a person can increase his/her communication exposure and involve himself herself with different organization s/he will be able to diversify his/her livelihood status.

\section{Conclusions}

This study has shown that non-farm income plays a very important role in augmenting farm-income as almost three-quarters of the respondents adopted a combination of farm and nonfarm strategy. This is an indication that farming alone is not an adequate source of income for the rural households. Therefore, promoting non-farm employment may be a good strategy for supplementing the income of farmers as well as sustaining equitable rural growth. This could be achieved through training programs directed towards training farmers in skills that can be used in non-farm jobs in their vicinity as well as improvements in infrastructure, education and financial markets. Specifically, engagement in nonfarm activities, apart from reducing income uncertainties and providing a source of liquidity in areas where credit is constrained, could increase agricultural 
productivity as it provides the resources necessary for investment in advanced agricultural technologies. The adoption of better technology is expected to be highly profitable and will encourage the transition from traditional to modern agriculture. Therefore, there is a need for the government to formulate policies to increase the availability of non- farm jobs in the rural areas. Further, the private sector should be encouraged to create income-generating activities in the rural areas to enhance their livelihood diversification activities and ultimately improve their living standard.

\section{Recommendations}

Proper action should be taken to ensure diversify livelihood portfolio in farm and non-farm sectors. Traditional norm may act as impediment to the diversify livelihood portfolio. So the farmers should be brought under strong motivational programs, which will help them come out of the traditional norms to properly practice livelihood diversification. Existing functional educational programmes for the farmers should be strengthened. This can be implemented through the involvement of local GOs and NGOs and the participation of the women farmers. Priority should be given by the concerned authorities for enhancing family education of the farmers through formal, non-formal training. The attitude toward livelihood diversification of a farmer enables one to enhance livelihood diversification. A farmer with favourable attitude easily adopt new diversified livelihood portfolio. It is, therefore, recommended that encouraging them to take part more in group discussions, training programmes, organizational participation etc. and increasing their exposures to various communication media so that attitude of the farmers become favourable. The various GOs and NGOs should design appropriate extension programmes and strategies.

\section{References}

Barrett, C. B., T. Reardon and P. Webb. 2001. "Nonfarm income diversification and household livelihood strategies in rural Africa: concepts, dynamics and policy implications, Food Pol. 26: 315-331.

Bryceson, D. 2000. Rural Africa at the Crossroads: Livelihood Practices and Policies. ODi Natural Resource Perspectives. 52.

Ellis, F. 1999. Rural Livelihood Diversity in Developing Countries: Evidence and Policy Implications ODi Natural Resource Perspectives. 40.

Ellis, F. 2000. Rural Livelihoods and Diversity in Developing Countries. Oxford University Press, USA.

Gordon A. and C. Craig. 2001. Rural non-farm activities and poverty alleviation in subSaharan Africa. Social and Economic Development Department. Natural Resources Institute. Policy Series. P. 14. 
Habiba, A. 2012. Livelihood diversification pursued by rural women farmer. Unpublished MS Thesis. Department of Agricultural Extension and Rural Development. Patuakhali Science and Technology University. Dumki, Patuakhali.

Matsumoto T., Y. Kijima and T. Yamano. 2006. The role of local nonfarm activities and migration in reducing poverty: evidence from Ethiopia, Kenya, and Uganda. Agric. Econ. 35: 449-458.

Ruben R. and M. Van den Berg. 2001. Non-farm employment and poverty alleviation of rural households in Honduras. World Develop. 29(3): 549-560.

Saha B. and B. Ram. 2010. Livelihood diversification pursued by farmers in West Bengal. Indian Research Journal of Extension Education. 10 (2). May 2010. 
